\title{
Maternal Death Reviews at a Tertiary Care Hospital
}

\author{
Indira Upadhyaya' \\ 'Paropakar Maternity and Women's Hospital, Thapathali, Kathmandu, Nepal.
}

\section{ABSTRACT}

Introduction: All pregnant women are at risk of obstetrical complications which occurs during labor and delivery that lead to maternal death. Here to report a 10 year review of maternal mortality ratio in "Paropakar Maternity and Women's Hospital (PMWH) Thapathali Kathmandu, Nepal.

Methods: Medical records of 66 maternal deaths were reviewed to study the likely cause of each death over the study period.

Results: There were a total of 66 maternal deaths. While 192487 deliveries conducted over the 10 year period. The maternal mortality ratio (MMR) was 356.64/100000 live birth. The highest MMR of 74.22/100,000 was observed in 2059 and lowest was 17.42/100,000 in 2068 B.S. Leading cause of MMR was remained hemorrhage accounting for $30.30 \%$ followed by eclampsia $24.24 \%$. Sepsis, suspected cases of pulmonary embolism and amniotic fluid embolism each contributing $15.15 \%$, $4.54 \%$ and $3.03 \%$ respectively. Where as anesthetic complication and abortion constitutes $6.06 \%$ each equally for maternal death. The death noted in older women $\left(30^{+}\right.$year) were $36.36 \%$. Primipara accounted for more deaths (51.51\%).

Conclusions: The fall in maternal mortality rate has been observed except for year 2063 BS. Hemorrhage is the main contributing cause behind maternal mortality.

Keywords: maternal mortality; maternal ratio; review causes of maternal mortality.

\section{INTRODUCTION}

World Health Organization (WHO) and United Nations International Children's Emergency Fund (UNICEF) reported on 2010 that approximately 358,000 women die worldwide from maternal causes, where $87 \%$ maternal death occurred in Africa and Asia. ${ }^{1-4}$ Nepal Demographic and health survey, showed the declined in maternal mortality rate (MMR) from 539/100,000 live births in 1998 to $229 / 100,000$ in 2008/2009, however still high than other affluent nations. ${ }^{5}$

Causes of maternal death in low income countries are postpartum hemorrhage, sepsis, hypertensive disorders in pregnancy and complications of abortion. ${ }^{3,6}$ Direct causes of maternal death are obstetrics complications; interventions omissions or incorrect treatment or sequence of events caused by any of the above and indirect causes that result from a pre-existing or pregnancy induced disease. Present study explores variants in maternal deaths in Paropakar Maternity and Women's Hospital (PMWH) during last 10 years.

Correspondence: Dr. Indira Upadhyaya, Paropakar Maternity and Women's Hospital Thapathali, Kathmandu, Email: drindira9@gmail. com, Phone No: 9851074598. 


\section{METHODS}

PMWH is a tertiary level hospital also a referral centre receives patient from all over the country. The hospital service is divided into 14 units having 415 beds. It provides reproductive health services, including familyplanning services, pre-natal clinic, and comprehensive emergency obstetric care services. Approximately 1924 deliveries take place per month at this hospital, of which $18 \%$ are cesarean deliveries. From recent days $24 \mathrm{hrs}$ lab facilities and blood transfusion service is available. Blood for transfusion is collected from volunteers or provided by the Nepal Red-cross society.

A review of maternal deaths was carried out using the 10 years data from 2059 Baisakh through 2068 Chaitra. The medical records of maternal deaths were studied. Information on all the cases were extracted from the patient's charts (notes) from statistics department of PMWH. The total deliveries and live birth for the period were noted from the delivery registers, including the demographic details pertaining to age parity and antenatal care. These women were either registered for delivery at the hospital; or were referred from another hospital or from home in case of an emergency. Prior to the study, the permission was obtained from hospital authority. Data was analyzed using Microsoft Excel.

\section{RESULTS}

There were 66 maternal deaths were occurred during these 10 years. Table 1 shows trends of maternal mortality ratio. Maximum death occurred in 2059 (MMR 74.22\%) and the death was in decreasing trends (MMR 17.42\%) in 2068 B.S which was the lowest MMR of these period, never the less a peak of MMR was observed in graph 2063 B.S (50.61\%). This trend of MMR can be observed in Figure 1.

World Health Organization. Trends in Maternal Mortality: 1990 to 2008. World Health Organization, 20 Avenue Appia, 1211 Geneva 27, Switzerland.

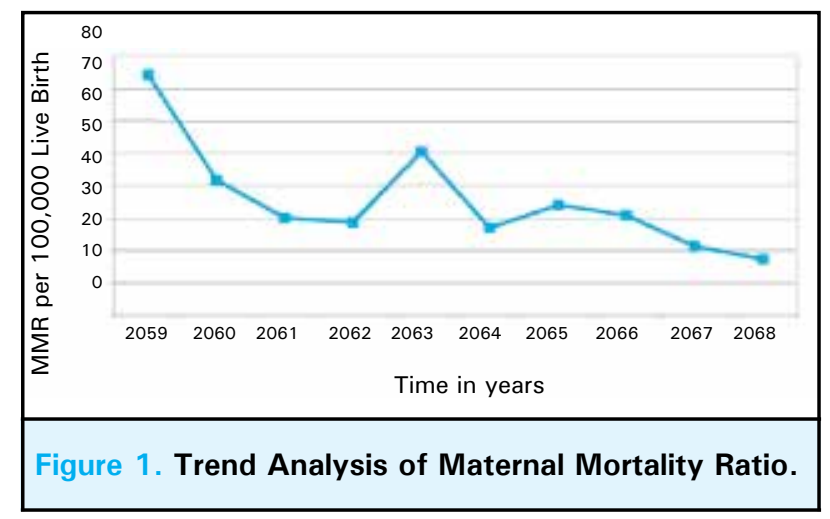

(Table 2) illustrates the causes of maternal mortality.
There were 20 cases of post partum hemorrhage (including 3 cases of uterine rupture, two involving previous LSCS scar and one grand multi para); 16 cases of hypertensive disorders (including severe preeclampsia- 6 and eclampsia -10); 10 cases postpartum sepsis; 4 cases of abortions; 4 cases involving complications of anesthesia; 3 cases of pulmonary embolisms and 2 cases involving amniotic fluid embolism.

\begin{tabular}{|c|c|c|c|}
\hline Year & $\begin{array}{l}\text { Total } \\
\text { Deaths }\end{array}$ & $\begin{array}{l}\text { Total Live } \\
\text { Births }\end{array}$ & $\begin{array}{l}\text { MMR/100000 } \\
\text { Live Births }\end{array}$ \\
\hline 2059 & 12 & 16167 & 74.22 \\
\hline 2060 & 7 & 16721 & 41.86 \\
\hline 2061 & 5 & 16601 & 30.11 \\
\hline 2062 & 5 & 17349 & 28.82 \\
\hline 2063 & 9 & 17784 & 50.61 \\
\hline 2064 & 5 & 18469 & 27.07 \\
\hline 2065 & 7 & 20483 & 34.17 \\
\hline 2066 & 7 & 22629 & 30.93 \\
\hline 2067 & 5 & 23327 & 21.43 \\
\hline 2068 & 4 & 22957 & 17.42 \\
\hline Total & 66 & 192487 & 356.64 \\
\hline
\end{tabular}

Mean age of these women was 27 years (range 17 to 42 years). Maternal death was high among para one women $(51.51 \%)$; followed by $(34.85 \%)$ among para 2-4 and least number was observed (13.64\%) in grand multipara. Maternal death was more $(59.05 \%)$ among women not attending ANC. Nearly $76 \%$ women of gestational age within 29-42 weeks and $6.6 \%$ women of 1-14 weeks of gestation died due to maternal causes. There were 11 postpartum maternal deaths (Nine home deliveries and two hospital deliveries). Around $60 \%$ patients were at critical condition at the time of admission about $67 \%$ cases were self referred which includes patients admitted through the ANC out patient department and emergency department. The patients who came through emergency department were the ones attending regular ANC in other hospital. Around $33 \%$ patients were referred from different institution in critically ill condition. About $41 \%$ deaths were during intrapartum and $42.42 \%$ were in postpartum period and $6.06 \%$ were associated with complications of abortion and molar pregnancy. Nearly $44 \%$ patients died within the first 24 hours after seeking care. Median length of hospital stay was one day (Table 3 ). 


\begin{tabular}{|c|c|c|c|c|c|c|c|c|}
\hline Year & $\begin{array}{l}\text { Hemo } \\
\text { rrhage }\end{array}$ & $\begin{array}{l}\text { SPE/ } \\
\text { Eclamp } \\
\text { sia }\end{array}$ & $\begin{array}{l}\text { Pulmo } \\
\text { nary } \\
\text { embolism }\end{array}$ & $\begin{array}{l}\text { Amnio } \\
\text { tic } \\
\text { Fluid } \\
\text { Embolism }\end{array}$ & Sepsis & Abortion & $\begin{array}{l}\text { Anesthetic } \\
\text { Compli } \\
\text { cation }\end{array}$ & $\begin{array}{l}\text { Indirect } \\
\text { cause }\end{array}$ \\
\hline 2059 & $4(33.33 \%)$ & $3(25 \%)$ & - & - & $2(16.67 \%)$ & $2(16.67 \%)$ & - & $1(8.33 \%)$ \\
\hline 2060 & $3(42.86)$ & $1(14.29 \%)$ & $1(14.29 \%)$ & - & $1(14.29 \%)$ & - & - & $1(14.29 \%)$ \\
\hline 2061 & $2(40 \%)$ & $1(20 \%)$ & - & - & - & - & - & 2 (40\%) \\
\hline 2062 & $1(20 \%)$ & $1(20 \%)$ & $1(20 \%)$ & - & $1(20 \%)$ & - & $1(20 \%)$ & - \\
\hline 2063 & 3 (33.33\%) & $3(33.33 \%)$ & $1(11.11 \%)$ & - & $1(11.11 \%)$ & - & - & $1(11.11 \%)$ \\
\hline 2064 & $2(40 \%)$ & $1(20 \%)$ & - & - & $1(20 \%)$ & $1(20 \%)$ & - & - \\
\hline 2065 & $2(28.57 \%)$ & $1(14.29 \%)$ & - & - & $2(28.57 \%)$ & - & 1 (14.29\%) & 1 14.29\%) \\
\hline 2066 & 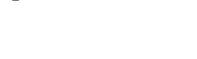 & $2(28.57 \%)$ & - & - & $2(28.57 \%)$ & $1(14.29 \%)$ & $1(14.29 \%)$ & $1(14.29 \%)$ \\
\hline 2067 & $2(40 \%)$ & 2 (40\%) & - & - & - & - & $1(20 \%)$ & - \\
\hline 2068 & 1 (25\%) & $1(25 \%)$ & - & $2(50 \%)$ & - & - & - & - \\
\hline Total & 20 (30.30\%) & 16 (24.24\%) & $3(4.54 \%)$ & 2 (3.03\%) & $10(15.15 \%)$ & $4(6.06 \%)$ & $4(6.06 \%)$ & $7(10.61 \%)$ \\
\hline
\end{tabular}

Table 3. Socio demographic and clinical characteristics of women who died due to maternal causes during the year 2059 to 2068 B.S.

\begin{tabular}{|c|c|c|c|c|c|}
\hline Characteristics & Frequency & Percent & Characteristics & Frequency & Percent \\
\hline Age (Year) & & & Condition on admission & & \\
\hline$<20$ & 8 & 12.12 & Stable & 26 & 39.39 \\
\hline $20-24$ & 16 & 24.24 & Critically ill & 40 & 60.61 \\
\hline $25-29$ & 18 & 27.27 & Referral status & & \\
\hline $30^{+}$ & 24 & 36.36 & Self & 44 & 66.67 \\
\hline Parity & & & Referred from different & 22 & 33.33 \\
\hline$P_{1}$ & 34 & 51.51 & Condition at time of death & & \\
\hline$P_{2-4}$ & 23 & 34.85 & Prenetal & 7 & 10.61 \\
\hline$P_{5}^{2-4}$ & 9 & 13.64 & Intrapartum & 27 & 40.91 \\
\hline Antenatal care (ANC) & & & Postpartum & 28 & 42.42 \\
\hline Yes & 27 & 40.91 & Complication of abortion & & 6.06 \\
\hline No & 39 & 59.09 & $\&$ molar pregnancies $1<$ & 4 & \\
\hline Gestational age (week) & & & 24 weeks pregnancy) & & \\
\hline $1-14$ & 4 & 6.66 & Interval between initiation & & \\
\hline $15-28$ & 1 & 1.51 & of care seeking \& death & & \\
\hline $29-42$ & 50 & 75.76 & $\leq 24$ & 29 & 43.94 \\
\hline Post partum & & & $25-48$ & 11 & 16.67 \\
\hline Home & 9 & 13.66 & $49-120$ & 16 & 24.24 \\
\hline Hospital & 2 & 3.03 & $\geq 120$ & 10 & 15.15 \\
\hline
\end{tabular}

Table 4 shows indirect $(10.60 \%)$ and direct $(89.39 \%)$ causes of maternal deaths. Preexisting disease 3 (heart disease); 3 jaundice and one acute gastro enteritis constituting indirect cause of maternal death, where as hemorrhage, hypertensive disorder, pulmonary embolism, amniotic fluid embolism, sepsis, abortion and anesthetic complications were the direct causes of maternal death. 


\begin{tabular}{|ll|}
\hline Table 4. Causes of maternal death. & \\
\hline Causes & Frequency \\
Indirect obstetric deaths & $7(10.6 \%)$ \\
Heart disease & 3 \\
Jaundice & 3 \\
Acute gastro enteritis & 1 \\
Direct obstetric death & $59(89.39 \%)$ \\
Postpartum & 17 \\
Uterine rupture & 3 \\
Eclampsia & 10 \\
Severe pre-eclampsia & 6 \\
Pulmonary embolism & 3 \\
Amniotic fluid embolism & 2 \\
Sepsis & 10 \\
Abortion & 4 \\
Anesthetic complication & 4 \\
\hline
\end{tabular}

\section{DISCUSSION}

During the reviewed period, total live births were 192487 and maternal deaths occurred were 66. The MMR of $356.64 / 100,000$ live birth calculated in this study were comparable of study done in tertiary care hospital from Punjab and Sindh having MMR's range of 228-2736/100,000 live birth. ${ }^{1}$ Available data shows that maternal mortality in Pakistan remain high that is 500 maternal deaths occur per 100,000 live births each year. ${ }^{1,7,8}$

Significant fall in maternal deaths was seen from 2059 (MMR $74.22 \%$ to $41.86 \%$ ) to 2068 B.S., where the number of live birth was almost same in number. The trend of decreasing MMR was studied from 2065 onwards to up till date and this could be due to the pilot program of Aama Surakchha Program launched by government of Nepal, Ministry of Health and Population. This program introduced free of cost delivery service, cash incentive (Nrs. 1000/-) to the patients for health facility delivery, cash incentive (Nrs. 300/- per patient) to the health professionals for attending the delivery case. The main objective of this program is to encourage safe delivery practices (SDP) among women, particularly from the poor and the marginalized communities by reducing the burden of financial cost at birth and encourage the tempo of work of health personal too. ${ }^{9}$

A study in Northern Nigeria in 2009 showed a dramatic drop in there yearly trends of maternal mortality from as high as $6234 / 100,000$ deliveries in 2003 to $1837 / 100,000$ deliveries in 2007 . Here eclampsia consistently remained the leading cause accounting $46.4 \%$ of the maternal deaths followed by sepsis and postpartum hemorrhage contributing $17 \%$ and $14.3 \%$ respectively. Grand multiparas accounted for a significant proportion of maternal deaths as compared to low parity. Lack of seeking antenatal care observed to be significant determinants of maternal mortality. Community enlightenment on the need to avail of antenatal care, hospital delivery services, improvement in the quality of skilled maternity care drastically curtail these preventable causes of maternal death and reduce maternal mortality rate. ${ }^{4,10} \mathrm{Nepal}$ and Bangladesh both have shown declines in maternal deaths despite low rate of deliveries with health professionals. It can be assumed that in addition to better Postabortion Care Consortium (PAC) (1995) and Comprehensive Abortion Care (CAC) services following legalization on March 2002 and emergency obstetrical care, fertility reduction and Aama Surakchha program launched on 2065/10/01 (14 January 2009) helped to reduce maternal mortality rate to $229 / 100,000$ live birth. The major intervention that took place to reduce maternal mortality rate in Bangladesh were family planning program, safe motherhood (midwives for normal delivery), equal access to comprehensive emergency obstetric care in public facilities and national program for social development and empowerment of women through education and micro credit program..$^{3,11,12}$

Pakistan has the highest maternal mortality rate among the south Asian countries where in most cases deaths are preventable. A study in a tertiary care hospital in Pakistan also identified that Pakistan, India and Bangladesh account for $46 \%$ of the world's total maternal deaths. In addition, study discussed hemorrhage, hypertensive disorder, sepsis and abortion as four major causes of maternal mortality in Pakistan. ${ }^{1,13}$

Hemorrhage was observed as the leading cause of maternal death accounting $30.30 \%$ in this study. Obstetric hemorrhage is the single most significant cause of preventable maternal deaths world wide accounting for $25-30 \%$ of all maternal deaths. ${ }^{14,15}$ It is interesting to note that hemorrhage is not only the biggest contributing factor in low resources countries, it is also the leading cause in the most developed nations. The most recent report from United Kingdom showed that 17 of 132 direct death were due to haemorrhage.$^{14}$ It was followed by severe preeclampsia and eclampsia covering $24.24 \%$ deaths. Data was near to the other study $27 \%^{1}$ and it is consistent with most of the death from Pakistan. Puerperal sepsis still prevalent in developing countries is still a highly lethal condition, even if its incidence is not so high. Sepsis being the cause in 3-19\% of all maternal deaths $(15 \%$ globally) ${ }^{16}$ is very near with present study $(15.15 \%)$. Abortion related death was observed as $6 \%$ of the total mortality. PAC and legalized CAC in country could have 
reduced the maternal deaths. Nearly $36.36 \%$ of deaths were observed in those above 30 years age which might be due to the increasing complications associated with increasing age. Around $52 \%$ death were in para 1 woman and only $13.64 \%$ were in grand multi para. It could be due to the patient's attitude of hiding repeated abortion and even perforated uterus. Maximum number of deaths happened in a pregnant lady at near the term (75.76\%) who were admitted for parturition or for observation because of severe pre-eclampsia, eclampsia and others.

The introduction of a combined preparation of oxytocin and ergometrine for intramuscular use followed by tablet mesoprostol and injection carboprost $\left(\mathrm{PgF}_{2}\right.$ alpha) intravenous and intramyometral may have helped to maintain the reduction in death from postpartum haemorrhage. The avoidance of unwanted high risk pregnancy in women of high parity, and possibly because of better prophylaxis in the $2^{\text {nd }}$ and $3^{\text {rd }}$ stages of labor shows that deaths from haemorrhage continued to fall between 2059 to 2068 B.S. Deaths from ruptured uterus have fallen considerably, perhaps because of increasing awareness of the dangers of excessive uterine stimulation with Oxytocic drugs, specially in women previously delivered by caesarean section or with possible cephalopelvic disproportion in labor.

Deaths from amniotic fluid embolism and pulmonary embolism are of relatively increasing importance and is hardly surprising because no advance has been made in its prevention, detection or treatment. The MMR from this cause has remained practically unchanged.

Complications of anesthesia were the fourth main cause of death. The reduction in deaths associated with anesthesia is probably due to the reduction in the use of general anesthesia. Maternal death rates associated with cardiac disease are dropping sharply. Among the deaths from acquired diseases, ischaemic heart disease now accounts for more causes than rheumatic heart disease. ${ }^{17}$ In this study three cases of heart diseases were recorded accounting the indirect cause of maternal death. Out of these, one was diagnosed case of rheumatic heart disease and two were diagnosed while they became critically ill in postpartum period and not even attended antenatal visits. Three cases were suffering with jaundice and one was with acute gastroenteritis which were considered rare during pregnancy but serious condition leading to maternal death.

\section{CONCLUSIONS}

Evidence based interventions are guide lines in reducing maternal mortality. Maternal death audits are a constructive way of learning. Although the fall in maternal mortality rate has been observed in recent years it still remains very high as compared to other countries. Hemorrhage is the main contributing cause behind maternal mortality.

\section{REFERENCES}

1. Fahim F, Nabeel $\mathrm{N}$ and Utman N. Trends in maternal mortality in tertiary care hospital in Peshawar- Pakistan. JPMI. 2012;26(4):422-7.

2. Rosmans C, Graham WJ; Lancet Maternal Survival Series steering group. Maternal mortality: who, when, where, why. Lancet. 2006; 368:1189-200.

3. Graham WJ. Now or never: the case for measuring maternal mortality. Lancet. 2002; 359(9307):701-4.

4. World Health organization. The World Bank. Maternal mortality 1990 to 2008: estimates developed by WHO, UNICEF, UNFPA and The World Bank. Geneva: WHO; 2010.

5. Vink N.M, de Jonge HC, Ter Haar R, Chizimba E.M, Stekelenburg J. Maternal death reviews at a rural hospital in Malawi. Int. J Gynaecol Obstet. 2013 Jan;120(1):74-7.
6. Cross S, Bell JS, Graham WJ. What you count is what you target: the implications of maternal death classification for tracking progress towards reducing maternal mortality in developing countries. Bull World Health Organ. 2010;88(2):147-53.

7. 8. Bano N, Chaudhri R, Yasmeen L, Shafi F, Ejaz L. A study of maternal mortality in 8 principal hospitals in Pakistan in 2009. Int J Gynaecol Obstet. 2011;114(3): 255-9.

8. 9. Government of Nepal Ministry of Health and Population. Department of Health Family Health Division. Teku Kathmandu. "Aama Surakchha Karyakram" Guideline 2065.

9. 10. Kullima AA, Kawuwa MB, Audu BM, Geidam AD, Mairiga AG. Trends in maternal mortality in a tertiary institution in Northern Nigeria. Ann Afr Med. 2009 Oct-Dec;8(4):221-4. 
10. 11. Hussein J, Bell J, Dar Iang M, Mesko N, Amery J, Graham W. An appraisal of maternal mortality decline in Nepal. PloS One. 2011;6(5):e19898.

11. Choudhury ME, Ahmed A, Kalim N, Koblinsky M. Causes of maternal mortality decline in Matlab, Bangladesh. J Health Popul Nutr. 2009;27(2):108-23.

12. Jafarey SN. Maternal mortality in Pakistan- complication of available data. J Pak Med Assoc. 2002:52:539-44.

13. Walfish M, Neuman A, Wlody D. Maternal haemorrhage. Oxford J. Med. BJA 2009: Vol. 103 (1); 147-156.
14. 15.Adekanle DA, Adeyemi AS, Fadero FF. Ante-partum haemorrhage and pregnancy outcome in LAUTECH teaching Hospital, Southwestern Nigeria. J Med Sci. 2011 Dec;2(12);1243-7.

15. 16. Dolea C, Stein C. Global burden of maternal sepsis in the year 2000: evidence and information for policy (EIP). Geneva: World Health Organization, 2003.

16. 17.Geoffrey C, Steer PJ. Turnbull's Obstetrics. $3^{\text {rd }}$ ed. Edinburg: Churchill Livingstone;2001.p.741-752. 